See Article page 145

\section{Commentary: Uniportal medial-basal segmentectomy: Unicorn or thoroughbred?}

\author{
Jules Lin, MD
}

Huang and colleagues ${ }^{1}$ demonstrate their approach to a uniportal medial-basal segmentectomy describing key steps, tips, and important anatomical variants. The authors provide a high-quality video, which should be watched first, with the figures and text reinforcing the steps. Although there has been an increase in segmentectomies with more small nodules found on lung cancer screening and we await the results from phase 3 , randomized trials evaluating sublobar resection versus lobectomy, including the Cancer and Leukemia group B 140503 trial $^{2}$ and the JCOG0802 trial, ${ }^{3}$ isolated basilar segmentectomies are more technically demanding and likely have a higher learning curve. In addition, segment 7 is the smallest and deepest basilar segment, and a segment 7 segmentectomy may have limited value for invasive cancers. Ueda and colleagues ${ }^{4}$ estimated that an adequate 2 -cm margin would only be achieved $20 \%$ of the time.

Segment 7 segmentectomy is less commonly performed because it is more technically challenging. It would be useful to know the experience level of the authors, and their thoughts on the learning curve for the uniportal approach as well as an isolated basilar segmentectomy. There are several anatomical variants, some of which they describe. Nagashima and colleagues ${ }^{5}$ categorized B7 branching patterns into 4 types, whereas Chujo and colleagues ${ }^{6}$ classified B7 and $\mathrm{A} 7$ branching patterns into 5 types.

\footnotetext{
From the Section of Thoracic Surgery, Department of Surgery, University of Michigan Medical Center, Ann Arbor, Mich.

Disclosures: The author reported no conflicts of interest.

The Journal policy requires editors and reviewers to disclose conflicts of interest and to decline handling or reviewing manuscripts for which they may have a conflict of interest. The editors and reviewers of this article have no conflicts of interest.

Received for publication March 9, 2020; revisions received March 9, 2020; accepted for publication March 11, 2020; available ahead of print April 1, 2020.

Address for reprints: Jules Lin, MD, Section of Thoracic Surgery, Department of Surgery, University of Michigan Medical Center, 1500 E Medical Center Dr, 2120TC/ 5344, Ann Arbor, MI 48109-5344 (E-mail: juleslin@umich.edu).

JTCVS Techniques 2020;2:149-50

2666-2507

Copyright (C) 2020 The Authors. Published by Elsevier Inc. on behalf of The American Association for Thoracic Surgery. This is an open access article under the CC BY-NCND license (http://creativecommons.org/licenses/by-nc-nd/4.0/).

https://doi.org/10.1016/j.xjtc.2020.03.004
}

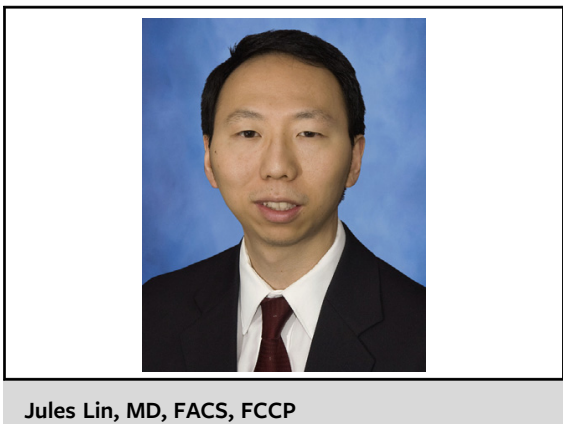

Jules Lin, MD, FACS, FCCP

CENTRAL MESSAGE
By demonstrating their approach
to a medial-basil segmentec-
tomy, the authors help surgeons
overcome the demanding
learning curve, but whether this
technique should be widely
adopted remains unclear.

To increase the chance of success, preoperative planning is crucial, and the authors show the utility of using chest computed tomography 3-dimensional reconstructions to determine the tumor location and the relationship between the segmental bronchial, arterial, and venous branches. $\mathrm{Xu}$ and colleagues ${ }^{7}$ found that 3-dimensional reconstruction was important, especially for preoperative planning for moderate to complex segmentectomies. The authors also describe the use of the inflation-deflation method to determine the segmental plane. Another useful technique is performing a perfusion study with indocyanine green after transecting the A7 pulmonary arterial branch to delineate the ischemic segment of the lung. ${ }^{8}$

Uniportal approaches to lobectomy and segmentectomy have become more commonplace in Asia, yet adoption remains low in the United States. The authors have demonstrated that a uniportal approach is possible, and although there are theoretical advantages to a single incision in terms of pain control, it is unclear whether there is a sufficient advantage over multiport thoracoscopic or robotic approaches to accept compromises in stapler and instrument angles. The stapler angle appears to be challenging in their video approaching the B7 bronchus straight on toward the lung parenchyma, whereas a multiport approach would provide a lower posterior stapler 
angle. The authors should consider using a curved-tip stapler that may be beneficial in passing the stapler around the bronchus.

Demonstrating their approach to a medial-basal segmentectomy may help surgeons overcome the demanding learning curve. However, it remains unclear whether this uniportal approach should continue to be a rare unicorn, with theoretical benefits in a limited subgroup of patients, or become a reliable thoroughbred that should be widely adopted as part of our armamentarium.

\section{References}

1. Huang L, Xu G, Li W, Chai Y. Uniportal thoracoscopic segmentectomy of medialbasal segment (S7) and its variants. J Thorac Cardiovasc Surg Tech. 2020;2:145-8.

2. Altorki NK, Wang X, Wigle D, Gu L, Darling G, Ashrafi AS, et al. Perioperative mortality and morbidity after sublobar versus lobar resection for early-stage non-small cell lung cancer: post-hoc analysis of an international, randomised, phase 3 trial (CALGB/Alliance 140503). Lancet Respir Med. 2018;6:915-24.
3. Nakamura K, Saji H, Nakajima R, Okada M, Asamura H, Shibata T, et al. A phase III randomized trial of lobectomy versus limited resection for small-sized peripheral non-small cell lung cancer (JCOG0802/WJOG4607L). Jpn J Clin Oncol. 2010;40:271-4.

4. Ueda K, Tanaka T, Hayashi M. What proportion of lung cancers can be operated by segmentectomy? A computed-tomography-based simulation. Eur J Cardiothorac Surg. 2012;41:341-5.

5. Nagashima T, Shimizu K, Ohtaki Y. Analysis of variation in bronchovascular pattern of the right middle and lower lobes of the lung using three-dimensional CT angiography and bronchography. Gen Thorac Cardiovasc Surg. 2017;65: 343-9.

6. Chujo M, Anami K. Branching patterns of segmental bronchi and arteries in the medial basal segment. J Bronchology Interv Pulmonol. 2014;21: 192-8.

7. Xu G, Chen C, Zheng W, Zhu Y, Chen H, Cai B. Application of the IQQA-3D imaging interpretation and analysis system in uniportal video-assisted thoracoscopic anatomical segmentectomy: a series study. J Thorac Dis. 2019; 11:2058-66.

8. Sun Y, Zhang Q, Wang Z, Shao F, Yang R. Is the near-infrared fluorescence imaging with intravenous indocyanine green method for identifying the intersegmental plane concordant with the modified inflation-deflation method in lung segmentectomy? Thorac Cancer. 2019;10:2013-21. 